\title{
A Risk Management Assessment of Rural Villages in Abhar County, Iran Using Spatial Analysis and Disaster Readiness Surveys
}

\author{
Mehdi Hajilo ${ }^{1 *}$, Lori Pennington-Gray ${ }^{2}$, Vahid Riahi $^{3}$, Amir Talkhab $^{4}$ \\ 1-PhD student in Geography and Rural Planning, University of Tehran, Iran \\ 2-Tourism Crisis Management Institute, Department of Tourism, \\ Recreation and Sport Management, University of Florida,USA \\ 3-Associate Professor of Geography and Rural Planning, University of Kharazmi, Iran \\ 4-MSc in Geography and Rural Planning, University of Tehran, Iran \\ * Correspondence: Mehdihajilo@ut.ac.ir Tel.: +98-936-2034285
}

\begin{abstract}
Understanding the vulnerability of areas and the likelihood of specific disasters, particularly earthquakes, is one of the most important issues in Iran. One of the major concerns in Iran is the resilience of rural communities. The present study is devoted to spatial analysis of risk in rural areas and the evaluation of preparedness in the rural districts of the city of Abhar. In particular, this study evaluates the resilience to earthquakes. The research was conducted in two parts in which the first part has used the VIKOR Multiple criteria decision making model as well as the employment of this model in the ArcGis. The second part of the study used field studies, in the form of questionnaires, to evaluate the readiness of the local population against the risks of earthquakes. Four indicators, individual, physical, economic abilities and access, were assessed. The population included rural districts, where statistical samples were villagers. Results of the spatial analysis indicated that 15 villages are in the high-risk areas, 24 villages were in the medium-risk areas and all other villages were in low-risk areas. In terms of readiness of the locals, the results indicated a lack of planning with regards to the four mentioned indicators.
\end{abstract}

Keywords: spatial analysis; risk taking; preparedness of local population; the City of Abhar 


\section{Introduction and Problem Statement}

Evaluating natural disasters over the past century shows a sharp increase in both frequency and intensity. In fact, the number of reported disasters in the world has increased over $25 \%$ from 1900 to 2011 [1]. Natural disasters are similar to other shocks, such as political conflicts, because they cause large losses in terms of human life and loss of infrastructure [2]. According to the International Disaster Database, the number of accidents reported in the world have increased from 1690 to 3886 from 1980 to 2009 [3].

Iran is considered to be among the world's most vulnerable countries due to its climate, geological characteristics and location. In addition, the disaster risk index of Nations Development Program (2004) indicates that Iran has the highest earthquake vulnerability in the world after Armenia. Amazingly, 31 of 40 types of natural disasters have occurred in Iran [4]. In fact, Iran is among the ten countries with natural hazards and is the sixth most earthquake-prone country in the world.

Earthquakes cause the highest human loss in Iran for various reasons, including the type of location, poor physical development and failure to comply with the necessary standards [5]. Earthquakes which occur in Iran are usually high magnitude spanning a width of $33 \mathrm{~km}$ and a depth of $50 \mathrm{~km} \mathrm{[6].} \mathrm{The} \mathrm{earthquake} \mathrm{hazard} \mathrm{zone} \mathrm{of} \mathrm{Iran} \mathrm{covers} \mathrm{more} \mathrm{than} 90$ percent of the country [7].

Earthquakes pose major threats to the welfare and development of rural communities [8]. When a natural disaster (earthquake) happens, it leaves irreparable effects on the environment, society and economy of rural areas [9]. Rural communities are in a more vulnerable position than urban centers because they are less likely to have the resources to plan for the impacts of unpredictable events [10]. Poor infrastructure of rural settlements and socio-economic inequalities have led to spatial turmoil in the country's settlement network and have increased the villages' vulnerability to natural disasters. Given these vulnerabilities, attention to planning is essential [11].

\section{The Case of the Bam Earthquake}

On December 23, 2003, Bam, Iran experienced a 6.5 magnitude earthquake. The earthquake resulted in more than 30,000 deaths, 20,000 injured and left more than 75,000 homeless. More than $85 \%$ of buildings were severely damaged or destroyed. Because of this catastrophic event, the importance of public awareness and community-based activities on reduction and management of disaster risk became evident to authorities. Thus, both government and non-government organizations created programs to promote public awareness and participation in earthquake risk reduction programs at both the local and national levels [12]. Small communities around the country became a focus for planning and risk management. 


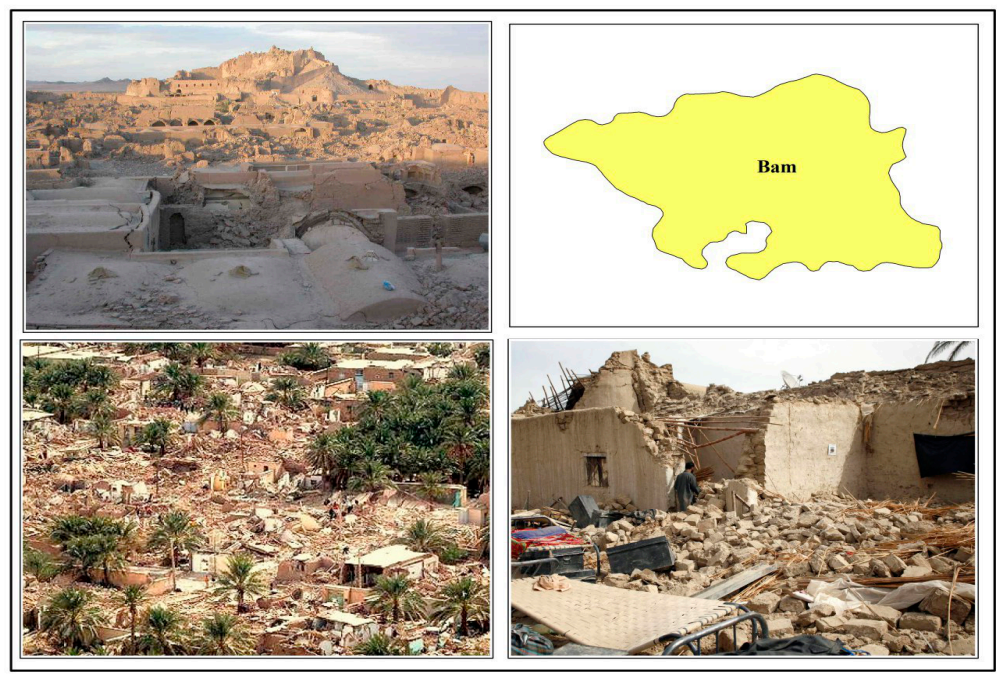

Figure 1. Map of Bam, Iran

Thus, the purpose of this study was to assess the spatial likelihood of an earthquake in North Central, Iran and the readiness of the villages to deal with an earthquake.

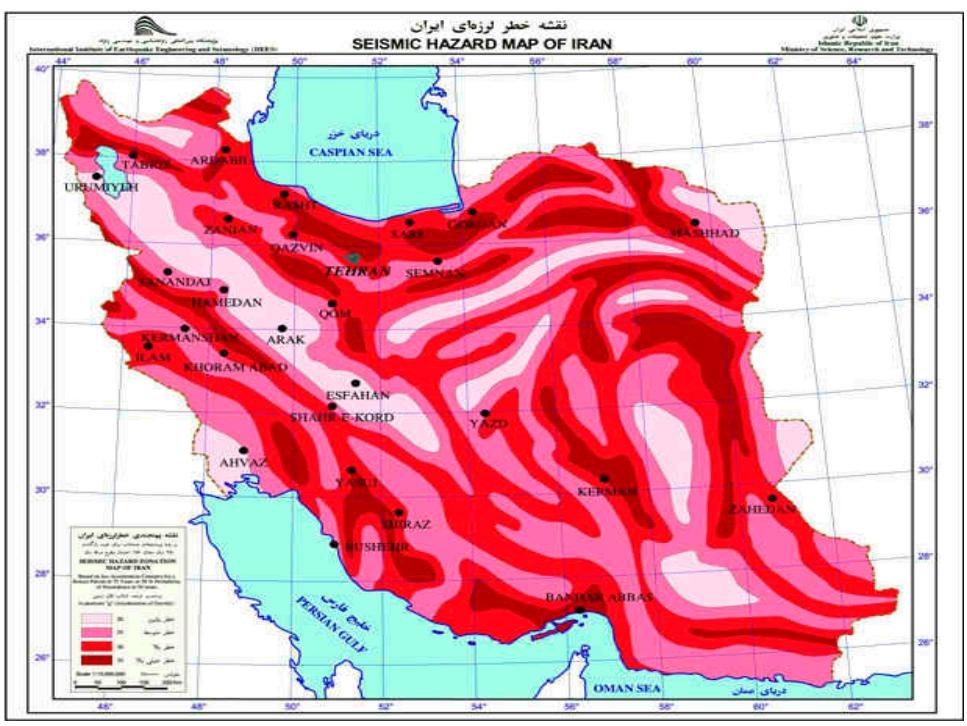

Figure 2. Seismic Hazard Map of Iran

\section{Literature Review}

\section{Risk Management}

There are many definitions of risk. Definitions originate from various sub-disciplines, such as health, environmental science, geography, communication and others. Within the field of geography, many of these definitions include references to the possibility of extinction, threats, high probabilities of incidents, favorable conditions for damage and actions which can lead to damage and/or serious injury [13].

Risk is an opportunity to cause damage to a person or a valuable asset through the occurrence of an event or hostile action [14]. Risk or uncertainties have been defined as the probability or likelihood of an incident occurring and the consequences of that incident. Knowing the source of a risk is always important [15]. High-risk events can have devastating consequences [16]. 
Risk management is the systematic application of management policies, procedures and practices to the tasks of establishing the context, identifying, analyzing, assessing, treating, monitoring and communicating. It is an iterative process. The management process is fairly prescribed and typically follows eight general steps: (1) Identify the risk, (2) Identify the causes, (3) Identify the controls aimed at reducing the likelihood or impact, (4) establish your likelihood and consequence descriptors, (5) establish your risk rating descriptors (i.e., low, moderate, high or extreme), (6) add other controls, (7) make a decision, and (8) monitor and review.

\section{Earthquakes as a Form of Natural Hazards}

Earthquakes have long been and are still considered one of the most dangerous natural hazards that a community can experience. They are typically associated and assessed as high risk. Earthquake risk is the likelihood that an earthquake will occur and the vulnerability of the community if it does occur.

The impacts of an earthquake leaves long-term social and economic damage to the environment. In fact, the earthquake may be considered as one of the deadliest natural hazards on the earth [17]. Most of the physical and economic damages of such incidents are due to lack of planning and poor building standards and infrastructures [18]. Strengthening building codes, enhancing infrastructure and educating the population are all measures that authorities can take to safeguard against the impacts of earthquakes.

After years of planning in relation to the risks of earthquakes, vulnerable structures and earthquake risk which have taken place separately in scientific and professional disciplines, it is now time for joint research with practical applications. Continuity and communication between municipal engineers, seismologists, geologists, mathematicians, computer science and risk management is not a simple task but efforts on projects which will improve science related to reduction of risks of earthquake are extremely useful and necessary [19]. In fact, the challenges associated with the allocation of resources to mitigate and rehabilitate and recover from natural disasters and man-made disasters are new theoretical questions for decision making in intertwined natural and human world [20].

A new approach has emerged and emphasized a structured and political process to implement laws and regulations in order to reduce the vulnerability of earthquake hazards, especially in urban areas [21]. This is necessary for the preparedness of residents of both urban and rural areas. This preparedness is an efficient and cost-effective method, which can help in, reducing the impacts caused by earthquakes. Undoubtedly, preparedness to respond and cope with earthquakes is fundamental to crisis management[22].

Preparedness includes measures aimed at improving safety of a destination [23]. In fact, preparedness in society to deal with earthquake is one of the most important factors in reducing earthquake damage. Removing the disaster is impossible but reducing its damages is possible and Community preparedness is considered as one part of the losses and waste reduction program [24].

Large and very destructive earthquakes are rare but when they do happen can lead to massive destruction. Since these incidents are rare, it is difficult for people to fully understand the full risk and thus the need to fully prepare. The goal of readiness is increasing the ability of residents to cope with and adapt to the demands and challenges of risks and the response and recovery from the disaster [25].

\section{Community Resilience and Community Readiness}

Disaster management training is meant to build competencies of disaster relief workers and volunteers about planning, response and recovery from disasters [26]. Assessment of disaster resilience using an index is often a key element of natural hazard management and planning [27] 
Community resilience denotes a community's ability to prepared itself in order to overcome changes and crises [28]. Community resilience is comprised of factors such as leadership, collective efficacy, social cohesion and place attachment. Physical components such as infrastructure and resources are additional aspects [29][30][31]. Resistance is an unlikely course for individuals and communities in the aftermath of disasters (see Fig. 3).

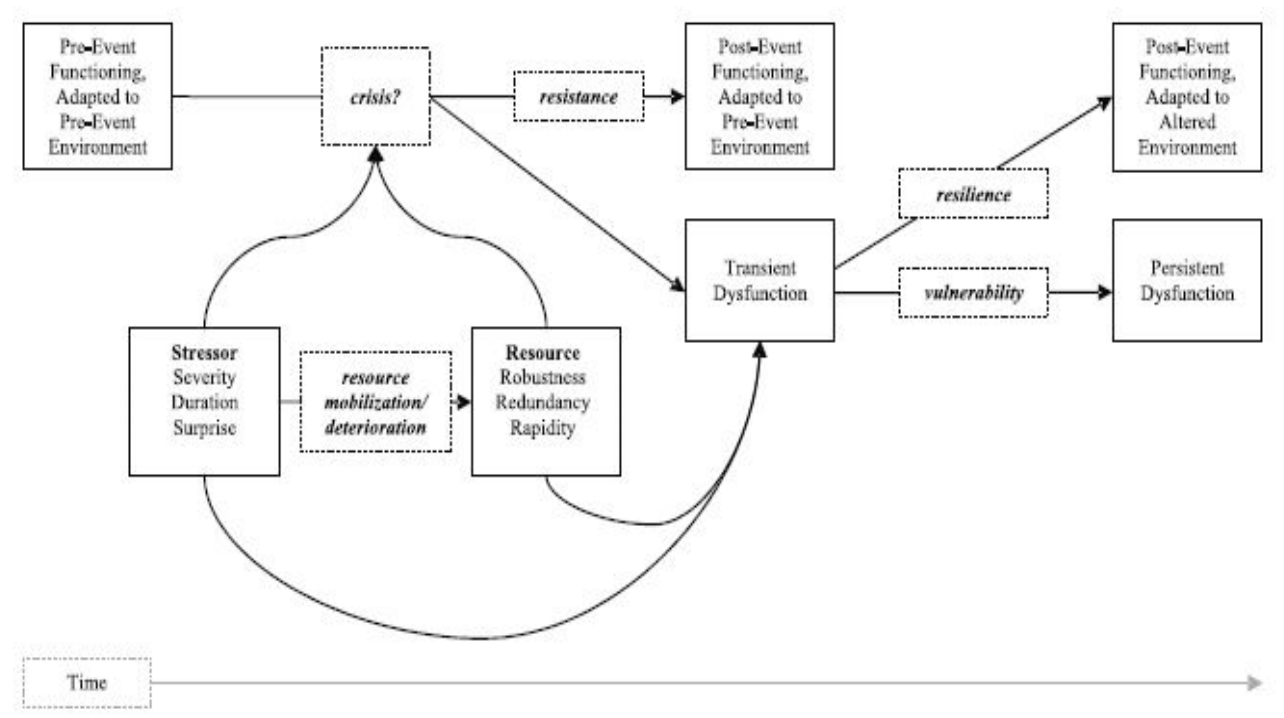

Figure 3. Model of stress resistance and resilience over time

Source: [32]

In fact, resilience theories exist for individuals, families, cities, communities, industrial sectors and even for physics and ecological systems [33]. The concept of community resilience describes the sustained ability of a community to take collective actions and to use available resources to selforganize, respond to, withstand, and recover from crises [34]. Norris and colleagues stated that community resilience emerges from four main capabilities; Economic Development, Social Capital, Information and Communication, and Community Competence [35].

\section{Natural Hazard Research in Iran}

Fazelnia and colleagues (2015) evaluated and studied landslides in order to find methods to reduce damage caused by those in a study titled "Natural risks hazard zoning in rural areas using geographic information system emphasis on landslide factor (Case Study: Dohezar village of Tonekabon city)" [36] The results showed that 25.88 square kilometers of the total area had a very low risk potential, 54.09 square kilometers had a low risk potential, 92.57 square kilometers had a medium risk potential, 85.57 square kilometers had a high risk potential and 34.50 square kilometers had a very high risk potential.

Meshkini et al (2014) studied the vulnerability of urban areas in Tehran, in a study entitled "Analysis of seismic vulnerability of the urban fabric" [37] and evaluated a series of physical, social and environmental indicators. Results indicated that the community had medium to high levels of vulnerability and those levels of vulnerability were higher in the eastern and southern regions. In a later study, Farahani et al (2014) sought to measure social, economic, institutional, physical and natural capacities of dealing with the impact of an earthquake. Results suggested that in Abhar city, Sonbolabad village in Iran there were several inadequacies, which existed, related to (earthquake) in the rural areas of Iran[38]. 
Qadiri and Nesbi (2015) evaluated risk vulnerability on a household level. They looked at mental attitudinal preparedness of households. In their study of Yazd, they examined preparedness of households to earthquakes using a quantitative method. They found that the level of mentalattitudinal preparedness of households is low overall and did not vary by neighborhood. However, the level of preparedness did vary by age, education, occupation, income and socio-economic status[22].

\section{The Study Site}

Abhar is a county in Zanjan Province in Iran. The capital of the county is Abhar. In 2006, the country's population was 158,544. The county has one district, the Central District and three cities: Abhar, Sain Qaleh and Hidaj. Zanjan Province is an agriculturally based county; the main crops are corn, oilseeds, fruits and potatoes.

It has an area of 22,164 sq. kilometers and occupies $1.3 \%$ of Iranian territory. Abhar is located on the 48 degrees 32 minutes to 49 degrees and 26 minutes east longitude and 35 degrees 43 minutes north latitude.

Abhar is surrounded by Tarom and Qazvin in the North, to Zanjan City in the Northeast and Ijrud in the East. Based on administrative divisions of 2011, Abhar city consists of the downtown area and five villages of Abharrud, Houmeh, Darsajin, Dolatabad and Saien Ghale.

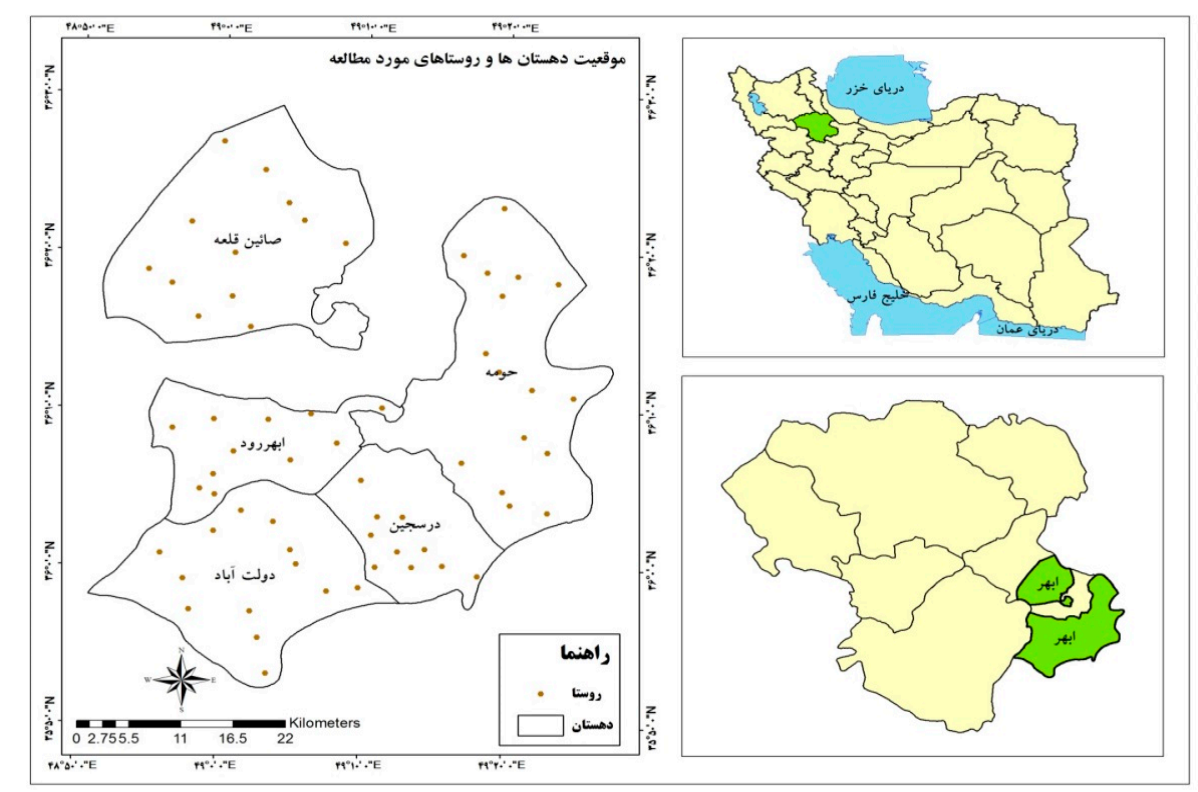

Figure 4. Location Map of the Study Area

\section{Research Methodology}

The present study is an applied research study which is aimed at evaluating the level of risk in rural areas as well as the readiness of the local population to mitigate against earthquakes. Documents and libraries as well as field study were used to address the research questions and conduct the study. 


\section{Research Question 1: Spatial Distribution of Vulnerability}

Ten indicators including (1) distance from rural health centers, (2) distance from urban health centers, (3) distance from roads, (4) distance from fire stations, (5) distance from active faults, (6) distance from minor fault, (7) distance from emergency centers, (8) population density, (9) soil type and morphology type and (10) slope, were used to evaluate the vulnerability of the village to earthquake.

Layers related to each of the indicators in ArcGis software were extracted and risk areas in the rural areas of Abhar city were identified by integration and implementation of the VIKOR model as one of the multi-criteria decision-making methods in ArcGis software. Then, the vulnerability of each of the villages was calculated. The results were entered into ArcGis software and were shown on a hazard map.

\section{Research Question 2: Field Study}

In regards to the field study, the study population consisted of Abhar city and Darsajin, Dolatabad, Saien Ghale, Houmenh, and Abharrud villages, which have the population of a total of 28024 people and 8227 households. Thus, the sample size was 379 individuals based on Cochran formula. A questionnaire was distributed to selected households (Table 5). Research questions were analyzed using T-Tests and one-way analysis of variance in SPSS.

$$
n=\frac{t^{2} p q / d^{2}}{1+1 / n\left(t^{2} p q / d^{2}-1\right)}=379
$$

Table 1. Evaluating the Status of Studied Region's Population and Method of Calculating Number of Samples In Region

\begin{tabular}{|c|c|c|c|c|c|c|}
\hline & Rural District & $\begin{array}{l}\text { Number of } \\
\text { Settlements }\end{array}$ & Population & $\begin{array}{l}\text { Number of } \\
\text { Households }\end{array}$ & $\begin{array}{c}\text { Number of } \\
\text { Samples In } \\
\text { Percent }\end{array}$ & $\begin{array}{c}\text { Number of } \\
\text { Questionnaires }\end{array}$ \\
\hline Central & Abharrud & 11 & 5126 & 1449 & $18 \%$ & 68 \\
\hline Central & The Suburbs & 16 & 6435 & 1885 & $23 \%$ & 87 \\
\hline Central & Darsajin & 10 & 1595 & 557 & $6 \%$ & 23 \\
\hline Central & Dolat abad & 13 & 3224 & 897 & $11 \%$ & 42 \\
\hline Central & Saien Ghale & 12 & 11644 & 3439 & $42 \%$ & 159 \\
\hline & Total & 62 & 28024 & 8227 & $100 \%$ & 379 \\
\hline
\end{tabular}




\section{Operationalization of the Variables}

With regards to operationalization of the variables, four indicators of readiness were measured: individual, economic, physical, and access ability. These measured the readiness of villagers to respond to the risks of an earthquake.

\section{Validity of the Measures}

Validity was measured with multiple methods. First, university professors were used to ensure the content and face validity of the 15 items on the questionnaire. In addition, a pre-test was sent to 15 professors and each of them responded to the questionnaire as well as sent their comments, corrections and deletions in order to improve the content validity of the constructs. Finally, Cronbach's alpha was used to assess the reliability which was used for internal consistency of the items. Table 2 contains the scores for each of the four indicators. Albeit the scores are low, they are still useable [39].

Table 2. Assessing the reliability of used indicators

\begin{tabular}{|c|c|}
\hline Indicator & Cronbach's alpha \\
\hline Individual ability & 0.71 \\
\hline Economic ability & 0.68 \\
\hline Physical ability & 0.75 \\
\hline Environmental ability & 0.73 \\
\hline
\end{tabular}

Source: Research Findings

\section{VIKOR multiple criteria decision making}

This method is an effective multi-criteria decision making tool and is used to solve problems with incompatible criteria. This method is used particularly when the decision maker is not able to express his/her preference at the beginning of process. In this method, the decision maker looks for a solution which is the closest solution to the ideal solution.

This model has been around since 1984. It is based on moving to collective agreement and is generally used to solve discrete problems. This method has been developed for multi-criteria optimization of complex systems. This method focuses on categorization and selection of options and results in a compromised solution to a complex problem by identifying conflicting criteria along the way in order to help decision-makers reach a final decision. Here, the compromised answer or general "consensus" is the closest answer to reasonable answer.

The VIKOR model prioritizes or ranks options based on evaluation of criteria. In this method, criteria are not weighted but rather assessed. Options are assessed and ranked based on the identified criteria and the value of indicators. The final step is to rank options based on the final score. The main difference between this model and the models of hierarchical or network decisionmaking is that unlike these models, these are no pairwise comparison between the criteria and options and each option is assessed independently by one criterion.

The advantage of a VIKOR model is that expert opinions are not necessarily required in this model to evaluate options based on criteria and raw data can rather be used. There is no need for scoring by experts. For example, "road" criteria can be measured and can enter the model without requiring expert assessment. The main difference with this model and network analysis models is that network analysis is based on pairwise comparison criteria and options. With the VIKOR model, there are no paired comparisons in this model between criteria and options; each option is rather evaluated independently based on any criteria. The evaluation can be based on raw data or expert 
opinion. Thus, the main objective is to determine the weight and value of each option as well as their ranking. The VIKOR algorithm includes the following steps [40]:

1. Formation of decision matrix

2. Making a scale: a linear method is used for this purpose

$$
N_{i j}=\frac{r_{i j}}{\operatorname{Max} r_{i j}}
$$

3. Determination of ideal positive and negative points

$$
\begin{gathered}
f_{i}^{*}=\operatorname{Max} f_{i j} \quad, i=1,2, \ldots, m \\
f_{i}^{*}=\operatorname{Min} f_{i j}, i=1,2, \ldots, n
\end{gathered}
$$

4. Determination of S utility and discontent indicators

$$
\begin{gathered}
S_{j}=\sum_{i=1}^{n} W \cdot \frac{f_{i}^{*}-f_{i j}}{f_{i}^{*}-f_{i}^{-}} \\
R_{j}=\operatorname{Max}_{i}\left[W \cdot \frac{f_{i}^{*}-f_{i j}}{f_{i}^{*}-f_{i}^{-}}\right]
\end{gathered}
$$

5. Calculation of the final indicator $(\mathrm{Q})$

$$
Q_{j}=v \cdot \frac{S_{j}-S^{*}}{S^{-}-S^{*}}+(1-v) \cdot \frac{R_{j}-R^{*}}{R^{-}-R^{*}}
$$

In the above equation:

$$
\begin{aligned}
S^{*} & =\min S_{j}, S^{-}=\max S_{j} \\
R^{*} & =\min R_{j}, R^{-}=\max R_{j}
\end{aligned}
$$

where $\left[\frac{S_{i}-S^{*}}{S^{-}-S^{*}}\right]$ indicates the ratio of distance from the negative ideal solution of $i-$ th option and in other words concurrence of a majority of i-th ratio.

Where $\left[\frac{R_{i}-R^{*}}{R^{-}-R^{*}}\right]$ indicates the ratio of distance from the ideal solution of i-th option and means opposition with i-th ratio.

6. Rank the options

Obtain three sorted lists from $\mathrm{S}$ and $\mathrm{R}$ and $\mathrm{Q}$ in this step.

7. Select the final option

The optimal solution (compromise) is an option which has the minimum $Q$ if the following two conditions are met:

A) The first condition is as follows:

$$
Q\left(A^{(r)}\right)-Q\left(A^{(1)}\right) \geq D Q
$$

In which $\mathrm{A}^{(1)}$ and $\mathrm{A}^{(2)}$ are respectively the first and second options and $D Q=\frac{1}{(i-1)}$ and $i$ are the number of alternatives. 
In case of violation of the first condition, both options are placed in optimal solutions

B) The second condition is that $\mathrm{A}^{(1)}$ must still have the best rank in terms of $\mathrm{S}$ or $\mathrm{R}$

In case of violation of the second condition, the set of optimal solutions will include the first to $\mathrm{m}$-th options in way that $\mathrm{m}$ shall meet the following conditions.

$$
Q\left(A^{(m)}\right)-Q\left(A^{(1)}\right)<D Q
$$

\section{Results}

\section{Research findings}

In this research, the risk zones in the study area were initially determined using the VIKOR model in ArcGis in order to evaluate the amount of risk in the rural areas. The following steps were taken for implementation of VIKOR model in ArcGis:

\section{Research Question 1: Spatial Distribution of Vulnerability}

\section{Step 1: Formation of a Location Decision Matrix}

In this step, raster layers were created based on the number of criteria used in this study using spatial analyst and the distance tool. In addition, the Feature to Raster tool was used to convert vector layers to Raster layers and IDW interpolation tool was used to create Raster layer of population density. Raster layers of used indicators are shown in the following figure (Figure 5).
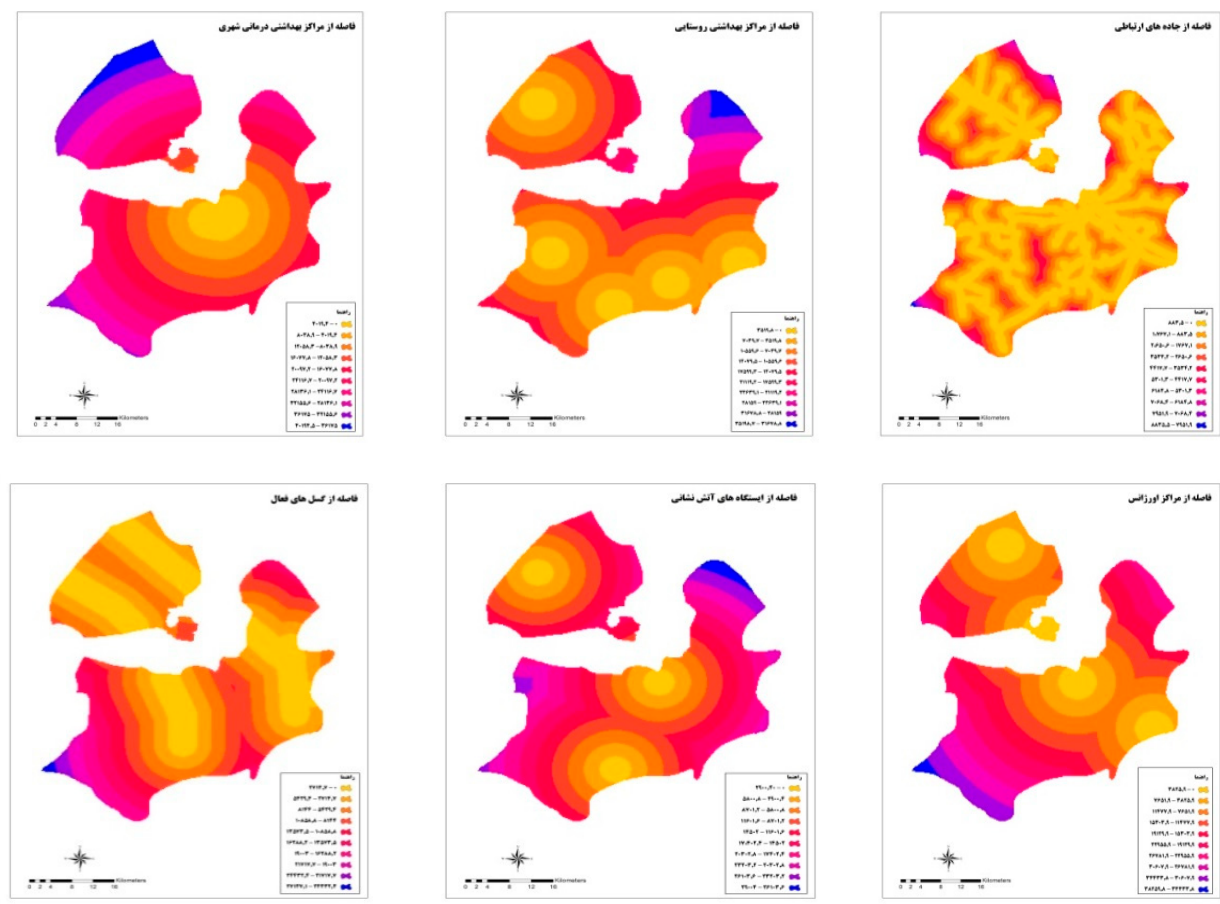

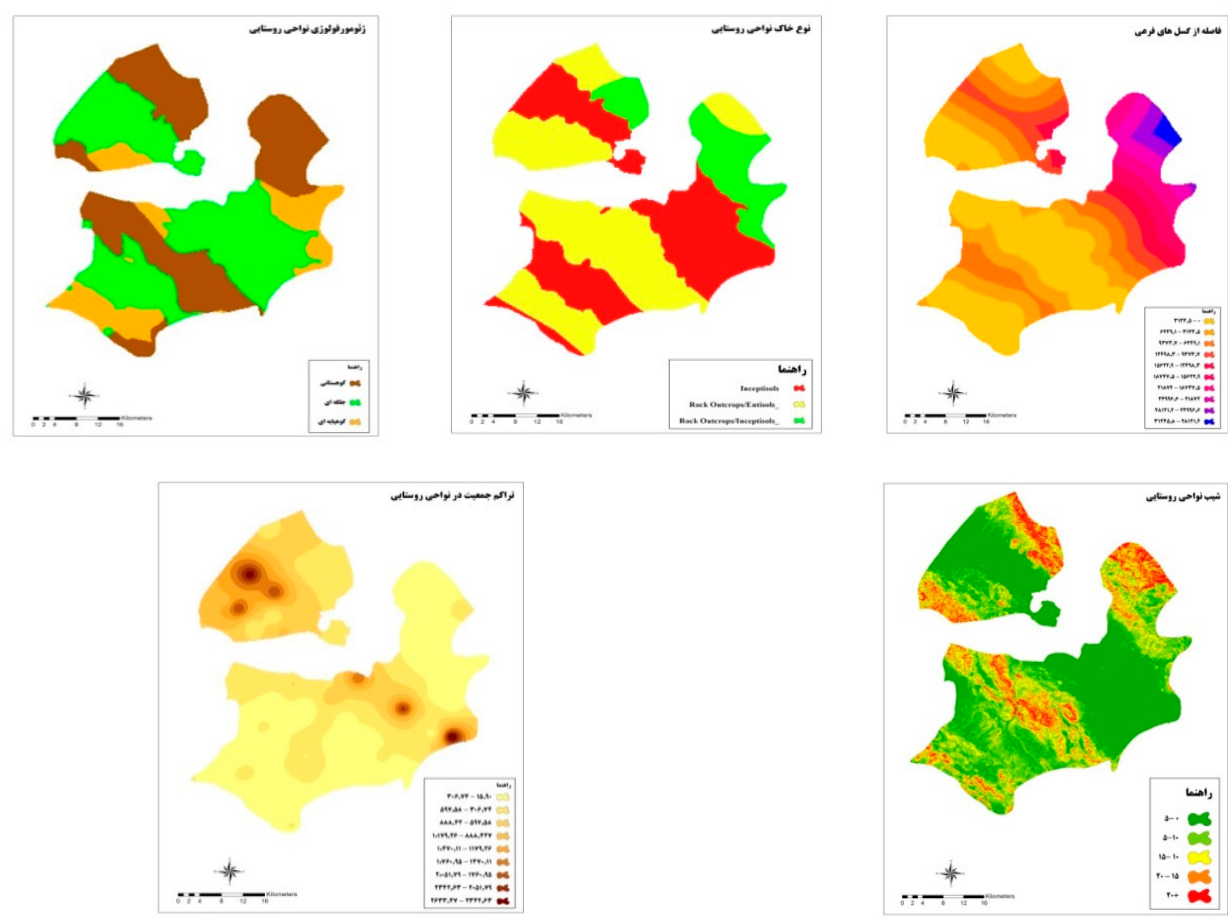

Figure 5. Raster Output of Risk Taking Indicators In Rural Areas

Source: Research Findings

\section{Step 2: Aligning the Indicator}

In this step, negative indicators were aligned using the Raster Calculator tool and all the indicators turned to positive direction. Its results are shown in the following figure (Figure 6).
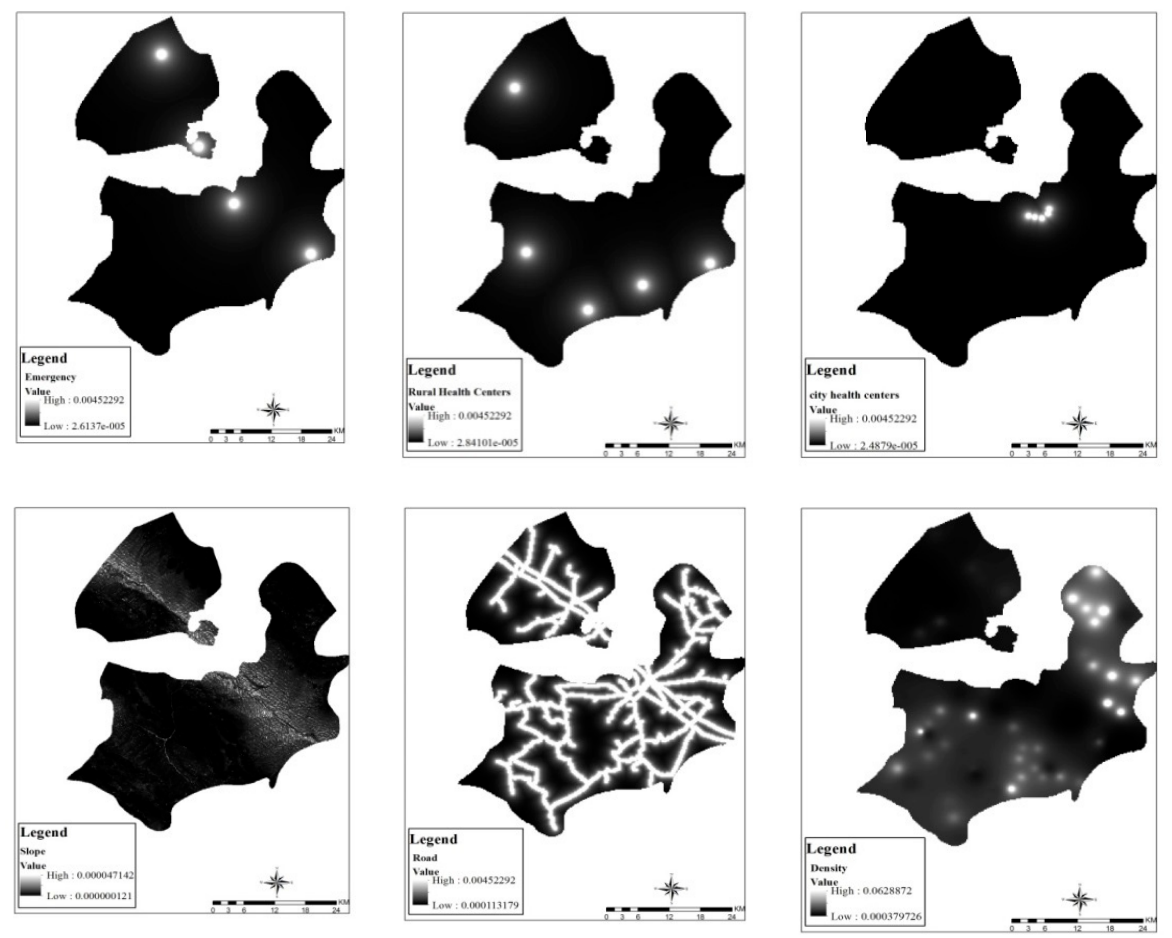


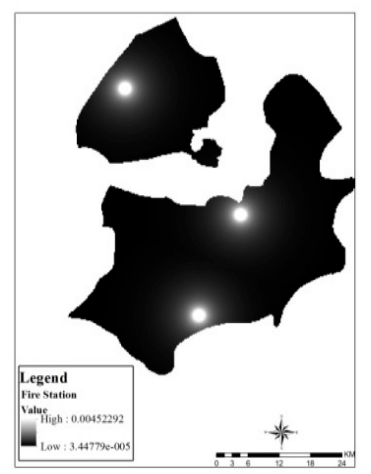

Figure 6. Same Direction Indicators Risk Taking In Rural Areas

Source: Research Findings

\section{Step 3: Calculation of positive $\left(F^{*}\right)$ and negative $\left(F^{-}\right)$ideals}

In this step, we found that different indicators have different effects on risk taking of rural areas. Some areas had a positive effect and some had a negative effect. Thus, we evaluated the distance between risky points within the ideal positive and negative points to determine the sky points. Given that all indicators have been aligned in a positive direction, only the ideal positive point was used which means villages with greater distance to these indicators have at greater risk of being impacted by an earthquake. In order to calculate the positive ideal of each criterion, the largest number of each layer was multiplied by the same layer in using the Raster Calculator tool.

\section{Step 4: Utility (S) and regret (R) indicators}

In this step, weights were obtained through the (AHP) technique and were applied to the criteria. In other words, the weighting operation was performed via the Raster Calculator tool and the weight of each indicator was multiplied separately by the standardized layers from the previous step. Weights of each of the indicators are shown in the Table below (Figures 7 and 8)

Table3. Weights of Indicators Used In Research

\begin{tabular}{|c|c|c|c|}
\hline Indicator & Weight & Indicator & Weight \\
\hline Rural Health Centers & 0.1 & $\begin{array}{c}\text { Access To The } \\
\text { Road }\end{array}$ & 0.1 \\
\hline Urban Health Centers & 0.09 & Slope & 0.05 \\
\hline Emergency Center & 0.12 & Morphology & 0.05 \\
\hline Fire Station & 0.08 & Soil & 0.05 \\
\hline Active Fault & 0.15 & $\begin{array}{c}\text { Population } \\
\text { Density }\end{array}$ & 0.13 \\
\hline Minor Fault & 0.08 & & \\
\hline
\end{tabular}

Source: Research Findings 


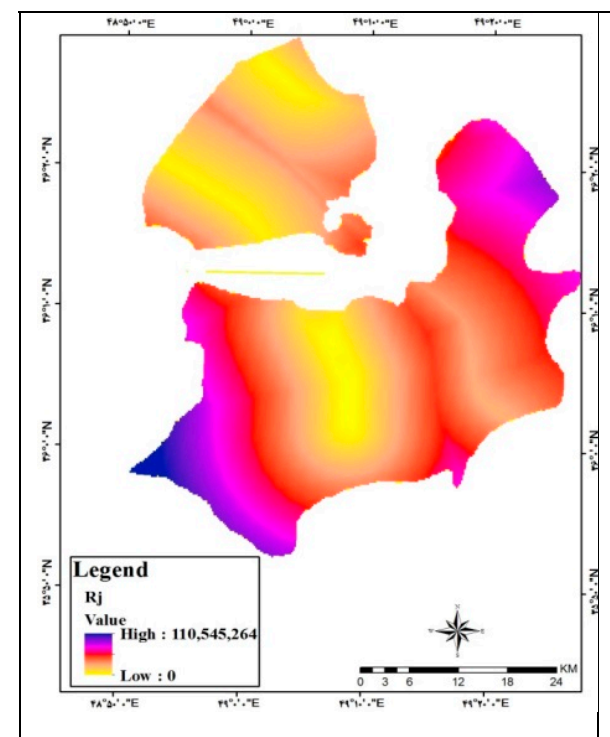

Figure 7. Rj layer

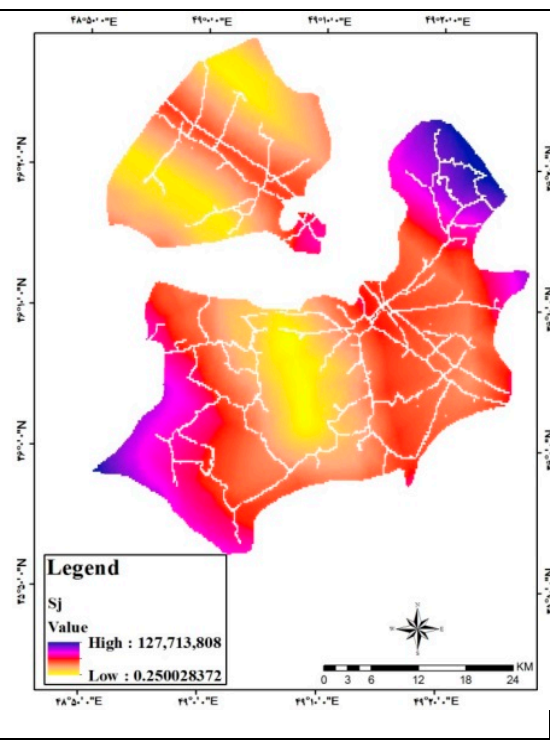

Figure 8. Sj layer

Source: Research Findings

\section{Step 5: Calculation of $(Q)$ indicator}

This step involves the calculation of the final scoring indicator which is $Q$. The $(\mathrm{Q})$ indicator must be between (0-1) and accordingly villages closer to zero are at a greater risk. Numerical value of the maximum and minimum $\mathrm{Sj}$ layer and Rj layer were inputted in the following equation in order to calculate the $\mathrm{Q}$ indicator in the GIS software.

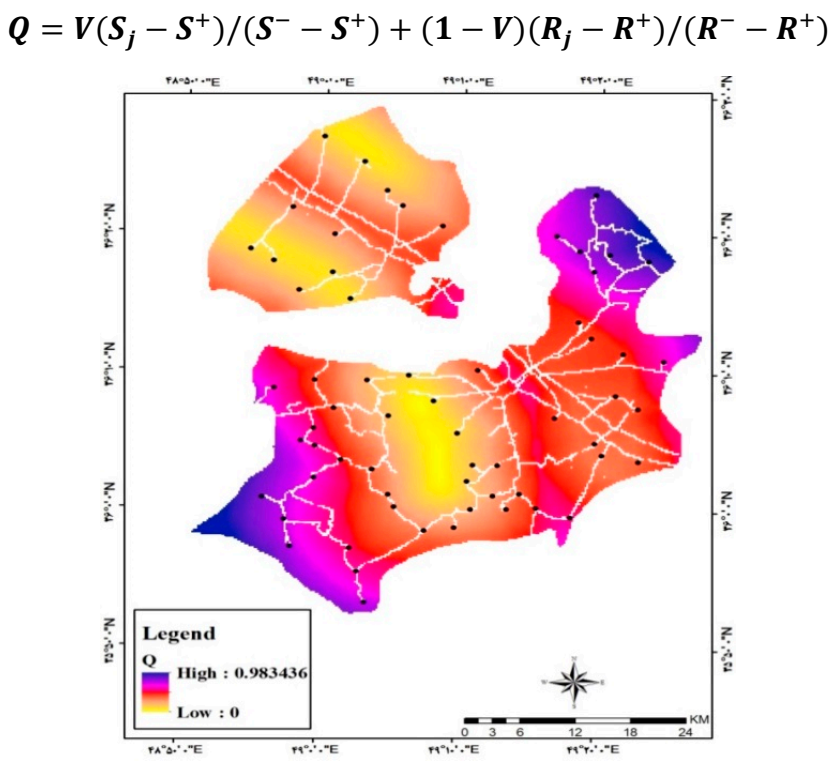

Figure 9. Spatial zoning of earthquake risk taking

With respect to the final layer index $(\mathrm{Q})$ of VIKOR model, villagers who are situated in an area closer to $(0)$ are at a higher risk. As shown by Figure 8, about 15 villages $(24.19 \%)$ are in a high risk area and 24 villages ( 38.70 percent) are in the moderate risk area and 23 villages (37.11\%) are in the low risk area.

In order to further explore the risk of a village to an earthquake, value of $\mathrm{Q}$ indicator was calculated for each of the villages in Excel and its data were entered into GIS and interpolation of value of $Q$ indicator was carried out using the Kriging tool. As shown in Figure 9, Cheshin and 
Elgriz have a higher risk potential followed by the villages of Aliabad, Hesarghajar, Ghovojogh, Khorasanlou and Jodaqiyeh. All other villages had a lower risk potential (Figure 10).

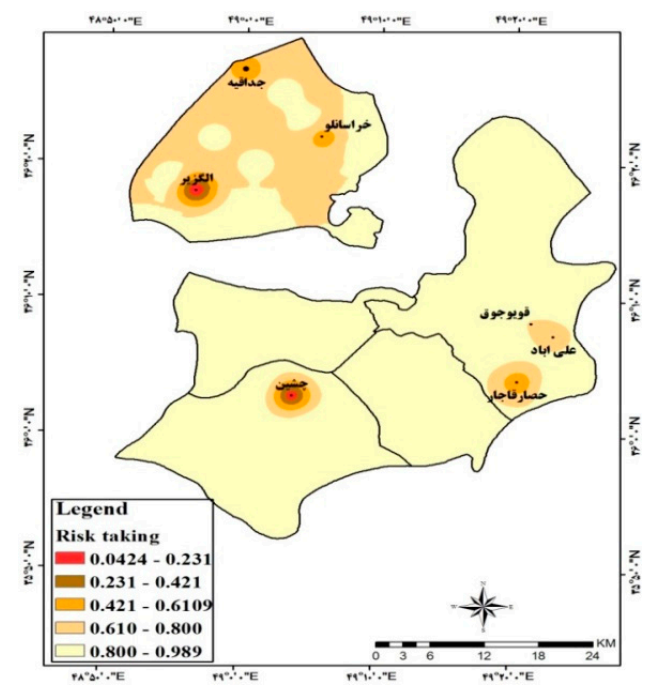

Figure 10. risk taking map of villages of Abhar city

Source: Research Findings

\section{Research Question 2: Field Study}

\section{Findings of the Study}

Finding 1: What is the level of readiness of local people in the event of an earthquake taking into account their physical, personal, economic and access indicators?

The results of the data analysis associated with each indicator to measure the readiness of villagers to deal with an earthquake showed. All four indicators were not significant. Concerning the physical indicator, the significance level was 0.320 which indicated a lack of significance. The significance level was 0.253 for the access indicator which indicated a lack of significance. The significance level was 0.069 for economic indicator which also showed a lack of significance. The final indicator, capability, indicated a significance level of 0.721 which also indicates a lack of significance with regards to capability and risk (Table 4). 
Table 4. Evaluating the Status of Studied Indicators from the Perspective of Villagers

\begin{tabular}{|c|c|c|c|c|c|c|c|}
\hline & \multirow{2}{*}{ 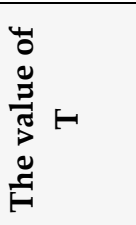 } & \multirow{2}{*}{ 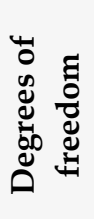 } & \multirow{2}{*}{ 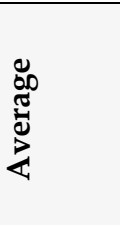 } & \multirow{2}{*}{ 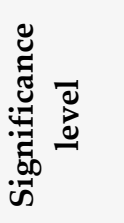 } & \multirow{2}{*}{ 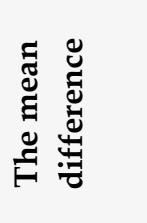 } & \multicolumn{2}{|c|}{$\begin{array}{c}95 \% \text { Confidence Interval } \\
\text { of the Difference }\end{array}$} \\
\hline & & & & & & Lower limit & $\begin{array}{l}\text { upper } \\
\text { limit }\end{array}$ \\
\hline Physical & -29.982 & 358 & 2.3682 & 0.320 & -0.73175 & -0.7798 & -0.6839 \\
\hline Access & -1.145 & 364 & 3.0648 & 0.253 & -0.03516 & -0.0995 & -0.0252 \\
\hline Economic & -44.857 & 365 & 2.2781 & 0.069 & -0.82186 & -0.8579 & -0.7858 \\
\hline $\begin{array}{l}\text { Individual } \\
\text { capability }\end{array}$ & -7.319 & 339 & 2.9902 & 0.721 & -0.10980 & -0.1393 & -0.0803 \\
\hline
\end{tabular}

Source: Research Findings

\section{Finding 2: Descriptive Statistics of Readiness}

Next, we examined the state of readiness of villagers against the risk of earthquakes. As it was mentioned, the status of assessed indicators was evaluated in form of four factors (individual abilities, economic status, the access and physical condition) from the perspective of villagers and then status of each of the evaluated items are presented from the perspective of villagers (Table 5). A descriptive analysis was run to demonstrate the descriptive statistics. 
Table 5. Evaluating the Status of Indicators

\begin{tabular}{|c|c|c|c|c|c|c|}
\hline 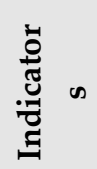 & Items & $\frac{3}{0}$ & 3. & : & in & $\sum^{2} \frac{0}{000}$ \\
\hline \multirow{12}{*}{ 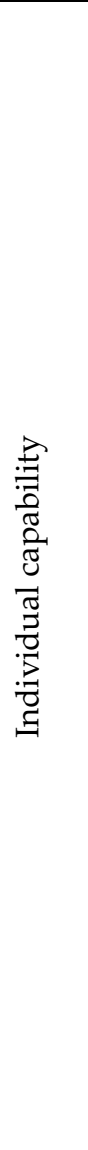 } & $\begin{array}{l}\text { Readiness to cooperate with the agencies and } \\
\text { organizations at the time of an earthquake disaster }\end{array}$ & 2.6 & 12.9 & 32.8 & 40.2 & 11.5 \\
\hline & $\begin{array}{l}\text { Readiness to cooperate with all the people of the } \\
\text { village at the time of earthquake disaster }\end{array}$ & 0.0 & 0.0 & 16.8 & 46.7 & 35.4 \\
\hline & $\begin{array}{l}\text { Readiness to comply with the principles Guide Plan } \\
\text { in new construction }\end{array}$ & 0.8 & 10.2 & 37.5 & 34.1 & 15.0 \\
\hline & Skills and knowledge about earthquakes & 25.5 & 37.8 & 24.9 & 9.4 & 1.0 \\
\hline & Familiarity with earthquakes through experience & 5.5 & 26.8 & 34.6 & 25.2 & 6.8 \\
\hline & $\begin{array}{l}\text { Familiarity with earthquakes by studying books and } \\
\text { articles }\end{array}$ & 38.3 & 23.9 & 19.4 & 9.7 & 7.1 \\
\hline & Familiarity with earthquakes by watching videos & 8.7 & 26.5 & 38.8 & 19.9 & 5.0 \\
\hline & Familiarity with earthquakes via the national media & 1.3 & 7.1 & 27 & 37.8 & 26.2 \\
\hline & $\begin{array}{l}\text { Participation in training courses in the event of an } \\
\text { earthquake }\end{array}$ & 58.8 & 25.7 & 11.3 & 2.6 & 80.0 \\
\hline & Knowledge of safe places & 1.6 & 8.9 & 28.3 & 38.1 & 22.3 \\
\hline & $\begin{array}{l}\text { Knowledge of relief groups in the village or sub- } \\
\text { district level }\end{array}$ & 2.1 & 19.7 & 39.4 & 25.7 & 12.9 \\
\hline & $\begin{array}{l}\text { Familiarity with the equipment needed in times of } \\
\text { Earthquake crisis (rescue bag) }\end{array}$ & 35.2 & 33.9 & 22.6 & 4.7 & 3.4 \\
\hline \multirow{5}{*}{ 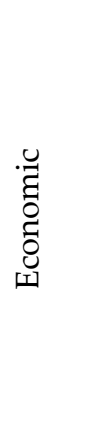 } & $\begin{array}{l}\text { Having enough capital to rebuild and repair old } \\
\text { dwellings }\end{array}$ & 29.7 & 32.3 & 36.2 & 1.6 & 0.0 \\
\hline & Having a proper job & 44.9 & 30.4 & 21.3 & 2.6 & 0.0 \\
\hline & Enough saving & 35.4 & 38.1 & 21.3 & 4.7 & 0.0 \\
\hline & $\begin{array}{l}\text { The ability to buy equipment and facilities related to } \\
\text { crisis situations (such as first aid boxes) }\end{array}$ & 3.9 & 33.1 & 53.8 & 8.1 & 0.0 \\
\hline & The ability to buy land in safe places & 1.3 & 25.7 & 56.4 & 15.0 & 0.3 \\
\hline \multirow{3}{*}{ 离 } & Easy access to home health and therapy centers & 6.8 & 28.9 & 37.5 & 22.8 & 1.8 \\
\hline & Easy access to aid groups and law enforcement & 8.7 & 22.0 & 49.6 & 17.3 & 2.1 \\
\hline & Easy access to secure areas of the village & 8.1 & 8.7 & 23.9 & 39.4 & 18.4 \\
\hline 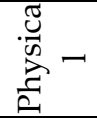 & $\begin{array}{l}\text { Quality of materials used in building and } \\
\text { construction }\end{array}$ & 3.9 & 31.8 & 41.7 & 2.2 & 1.8 \\
\hline
\end{tabular}




\begin{tabular}{|l|l|r|r|r|r|}
\hline The monitoring carried out on construction & 21.3 & 42.0 & 294.0 & 6.6 & 0.3 \\
\cline { 2 - 5 } Using local materials & 13.2 & 15.3 & 55.8 & 9.6 & 6.1 \\
\hline $\begin{array}{l}\text { The trend of modern architecture (construction with } \\
\text { reinforced concrete and skeleton) }\end{array}$ & 18.1 & 21.6 & 41.7 & 11.8 & 6.8 \\
\cline { 2 - 5 } New buildings and structures (made 1-4 years ago) & 11.4 & 17.0 & 39.8 & 25.7 & 6.1 \\
\hline $\begin{array}{l}\text { Using the advice of local architects in the } \\
\text { construction of housing }\end{array}$ & 9.2 & 33.1 & 35.7 & 17.6 & 3.1 \\
\cline { 2 - 6 } $\begin{array}{l}\text { Guide plan in the construction of housing } \\
\text { Insurance of buildings and structures }\end{array}$ & 81.6 & 13.9 & 1.8 & 0.5 & 0.0 \\
\hline
\end{tabular}

\section{Source: Research Findings}

\section{Finding 3: Relationship between Indicator Item and Village}

The status of the villages with regard to each of the mentioned indicators (individual abilities, economic status, the access and physical condition) was measured. The results showed that in relation to individual abilities, only two villages (Darsajin and Saien Ghale) were in a favorable situation in relation to mentioned indicator (mean score: 3.0395 and 3.0230, respectively).

In terms of economic status, the results showed that in general, the status of the all indicators were lower than the optimal level.

In terms of physical condition, the results showed that one village (Saien Ghale village) was in favorable condition (mean score: 3.2526 ).

Finally, the results showed that the access indicator was favorable for three of the five villages, Darsajin, Saien Ghale and Houmeh with mean scores of 3.3247, 3.1449 and 3.1349, respectively). In contrast, two villages, Abharrud and Dolatabad were at a disadvantage in terms of readiness (Table 6).

Table 6. Comparison of Status of Studied Villages In Relation To Indicators

\begin{tabular}{|c|c|c|c|c|c|c|c|c|}
\hline & & 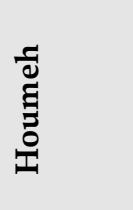 & 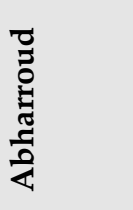 & 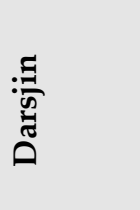 & 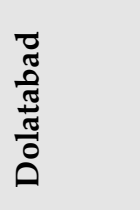 & 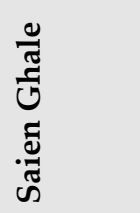 & 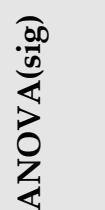 & 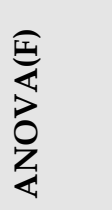 \\
\hline \multirow{2}{*}{$\begin{array}{l}\text { Individual } \\
\text { Capability }\end{array}$} & Average & 2.9605 & 2.9417 & 3.0395 & 3.9459 & 3.0230 & \multirow[t]{2}{*}{.275} & \multirow[t]{2}{*}{1.288} \\
\hline & SD & 0.25649 & 0.26899 & 0.21937 & 0.33805 & 0.27838 & & \\
\hline \multirow[t]{2}{*}{ Economic } & Average & 2.2889 & 2.3061 & 2.3478 & 2.3756 & 2.2245 & \multirow[t]{2}{*}{.084} & \multirow[t]{2}{*}{2.075} \\
\hline & SD & 0.33166 & 0.31422 & 0.39643 & 0.40049 & 0.34890 & & \\
\hline \multirow[t]{2}{*}{ Physical } & Average & 2.1210 & 2.1492 & 2.2609 & 2.0850 & 3.2526 & \multirow[t]{2}{*}{.000} & \multirow[t]{2}{*}{17.123} \\
\hline & SD & 0.27144 & 0.34072 & 0.30412 & 0.36763 & 0.39983 & & \\
\hline \multirow[t]{2}{*}{ Access } & Average & 3.1349 & 2.7576 & 3.1449 & 2.3421 & 3.3247 & \multirow[t]{2}{*}{.000} & \multirow[t]{2}{*}{37.791} \\
\hline & SD & 0.47457 & 0.55944 & 0.38699 & 0.49312 & 0.49095 & & \\
\hline
\end{tabular}


It is also worth noting that the status of each of these indices was studied at the total level of villages using Anova test and Duncan's post-test. The results showed that in relation to the access index, the level of significance was equal to 000 and the value of the $F$ test was 37.791, meaning that there was a significant difference between the villages in terms of the indicator. The villages were divided into three groups, the Duncan test revealed that Sayeen Qaleh village had an average of 3.3247 and was the most "ready" community. As opposed to the village of Dolatabad, which had a rating of 2.3421 .

With respect to the physical index, the results showed that the level of significance for the total villages was equal to 000 and the value of the $\mathrm{F}$ test was 17.123. This means that the villages showed a significant difference in terms of physical index of readiness. The village of Sain Qaleh had an average of 2.5645 while Dolatabad had an average of 2.0850, indicating a less ready community. However, it should be noted that in relation to economic and individual indicators, there were no meaningful differences between the total village's perceptions of readiness.

\section{Conclusion}

Iran is considered as one of the most hazardous countries in the world with regards to earthquakes and seismic risk. This is problematic in general, but for many rural communities, it is even more problematic. Rural areas face heavier losses of life and greater property destruction typically. This is often a result of several factors: use of substandard materials, failure to comply with technical and engineering standards and lack of compliance of construction standards. In addition, rural communities are typically more vulnerable in terms of community resources, individual capabilities, community infrastructure and access. Thus, evaluation of the vulnerability and risk taking levels of villages is necessary to determine how government officials can help reduce and mitigate the impacts of earthquakes in rural communities. Thus, the aim of this study was to evaluate the risk of earthquake likelihood as well as village readiness in rural areas in Iran.

Abhar City was selected as the study site due to the likelihood that an earthquake will happen in the next decade. Abhar sits on an active fault and is also surrounded by multiple other faults. Initially, hazard zoning was carried out to evaluate the risk of earthquakes within the rural areas of Abhar. A Vikor model and ArcGis was used. The results of the final hazard zoning map showed that 15 villages were in the high-risk area (yellow area), 24 villages are in a moderate risk area (red area) and all remaining villages were in a low risk area.

Earthquake risk was evaluated separately and $Q$ indicator was calculated for each village. The results showed that two villages had a moderate risk potential, while six villages were among the riskiest villages in Abhar. Given that villages are scattered across the city and had a significant populations within them, planning within these villages is necessary to help reduce the risk within these villages. The ranking of likelihood and readiness of the village will help decision makers prioritize which villages need education, training and planning first.

These findings also help emergency managers to be able to move villagers to less risky areas within the city, in the event of an earthquake. The revelation of these safe areas can provide information for elected officials to approve funding for enhanced building safety. If these areas are to be used for evacuation or shelters, investment in the infrastructure in this area can help to strengthen existing buildings to shelter villagers in the event of an earthquake. Textures and type of materials used, which are typically cheaper and less resistant can be enhanced.

Also, the results of this study find that in relation to the indicators (personal, economic, physical abilities and access) villagers are not highly knowledgeable or engaged in the readiness function of disaster management planning. In the 15 high-risk zones, villagers need to increase disaster management skills, knowledge, abilities and self-efficacy. In particular, two villages of Doltabad and Abharroud are in a far worse position with regards to readiness capacities than the other villages. These villages need immediate attention given they are situated in a high risk zone. 
In all, it is necessary for villagers to be trained and enhance knowledge of disaster planning. In addition, villages need to have investments in infrastructure and management in order to reduce the impacts of an earthquake in this particular rural setting.

\section{References}

1.CRED.(2012). "Trends and Relationships Period 1900-2011", The International Disaster Database: http://www.emdat.be, (December 10, 2012).

2.Gignoux Jérémie, Menéndez Marta(2016),Benefit in the wake of disaster: Long-run effects of earthquakes on welfare in rural Indonesia, Journal of Development Economics 118 (2016) 26-44.

3.Escap, \& Unisdr, (2011). Protecting development gains: reducing disaster vulnerability and building resilience in Asia and the Pacific. The Asia Pacific Disaster Report, United Nations. Retrieved April 10, 2013, from http://www.unisdr.org/files/29288_apdr2012finallowres.pdf

4.Rezaei, Mohammad Reza, Rafieian, Mojtaba Hosseini, Seyed Mostafa, (2015), measuring the physical resilience of urban communities against earthquakes (Case Study: Tehran's neighborhoods), Journal of Human Geography Research, Volume 47, Number 4, Winter, pp. 623-609.

5.Gholami, Yunes, Hayati, Salman, Ghanbari, Mohammad, Esmaieli, Asiye, (2015), predicted an earthquake in Mashhad vulnerable spaces, urban planning Geography Research Quarterly, Volume 3, Number 1, Spring, pp. 67- 55.

6.Anabestani, Aliakbar, (2008), Doruneh and the establishment of human settlements in the region of Kashmar, Geographical Journal, the fortieth year, No. 63, Tehran.

7.Wisner, B, Blaikie, P, Cannon,T, Davis,L., 2003. At risk:natural hazardous, peoples vulnerability and disasters, Second edition.

8.Pour Taheri, Mehdi, Haji Nejad, Ali, Fatahi, Ahdallh, Nemati, RReza, (2014), assessment of the physical vulnerability of rural settlements against natural hazards (earthquakes) with Copperas Decision Making Model (Case Study of Rural District There Chalanchulan city ), Journal of Spatial planning, Volume XVIII, No. 3, fall, pp. 52-29.

9.Parishan, Majid, (2011), risk management, environmental hazards, earthquake risk in rural areas, thesis Geography, Faculty of Humanities, Tarbiat Modarres University, Tehran.

10.Yodmani, S. (2000). Disaster risk management and vulnerability reduction: Protecting the poor. Retrieved May 15, 2013, from http://www.adpc.net/infores/adpc-documents/ povertypaper.pdf, (2000). P.34

11. Zaheri, Mohammed, Aghayari Hare, Mohsen, Zakeri Miyabi, Kolsum, (2015), rural areas of earthquake vulnerability assessment (Case study: the central city of Marand), Journal of Research and rural planning, Vol. 4, No. 1, Spring, successive Number 9, pp. 111-97.

12.Amini Hosseini Kambod, Hosseini Maziar, Izadkhah YasaminO, Mansouri Babak, Shaw Tomoko(2014), Main challenges on community-based approaches in earthquake risk reduction: Case study of Tehran, Iran, International Journal of Disaster Risk Reduction Volume 8, June 2014, Pages 114-124.6.

13.Abdullah Khani, Ali, (2006), review the security theory, Journal of Strategic Studies, No. 33, Tehran.

14.Woodruff, J. M. (2005). “Consequence and likelihood in risk estimation: a matter of balance in UK health and safety risk assessment practice". Safety Science,43(5e6), 345e353.

15.Noorollahi, Hanieh, Barzegar, Akram, Avaz Abadian, Farshid, Soleimani, Atedeh, Alikhani, Arezu, (2015) present a model of risk assessment (risk) based on a combination of performance and planning approaches in critical infrastructure, the Journal and Research crisis management, seventh, spring and summer, 56- 47.

16. NSW (New South Wales) Department of Finance and Services (2011). Project Risk Management Guideline, Version 3.3, NSW Government, Finance and Services, p417. 
17.Santos reyes Jaime, Gouzeva Tatiana, Santos-reyes Galdin,(2014), Earthquake risk perception and Mexico City's public safety, "2014 ISSST”, 2014 International Symposium on Safety Science and Technology, Procedia Engineering 84,662-671.

18.Linares- Rivas, Alejandra.; (2012). Panama Prepares the City of David for Earthquakes, Project Highlights issue 9, Panama, pp 1- 4.

19.Lutman Marjana, Šket Motnikar Barbara, Weiss Polona, Klemenc Iztok, Polona, Matej Cerk, Jeraj Julij, Banovec Primož, Zupancic (2014), Aspects of earthquake risk management in Slovenia, 4th International Conference on Building Resilience, Building Resilience 2014, 8-10 September2014, Salford Quays, United kingdom, Procedia Economics and Finance $18,659-666$.

20.He fei , Zhuang Jun(2016), Balancing pre-disaster preparedness and post-disaster relief, European Journal of Operational Research 252 (2016) 246-256.

21.Manandhar Bikram (2016),Remittance and earthquake preparedness, International Journal of DisasterRiskReduction15,52-60.

22.Qadiri, Mahmoud, Nesbi, Nastaran, (2015), analysis of attitudinal difference in mental preparation households in the city against earthquakes, geography, urban planning research journal, Volume 3, Issue 2, Summer, pp. 245- 227.

23.Sutton J. \& Tierney K. (2006), Disaster preparedness: Concept, Guidance and Research, Natural Hazards Center, Institute of Behavioral Science, University of Colorado Boulder.

24.Abdullahi, Majid, (2004), crisis management in urban areas, publications, organizations, municipalities and RMs country, Third Edition, Tehran, 136 pp.

25.Paton Douglas, Anderson Ella, Becker Julia, Petersen Jessica(2015), Developing a comprehensive model of hazard preparedness: Lessons from the Christchurch earthquake, International JournalofDisasterRiskReduction14,37-45.

26.Nisa Nik Nazli, Nik Nadian, Sipon, Sapora, Radzi, Husni Mohd(2014), Analysis of Training Needs in Disaster Preparedness, Procedia - Social and Behavioral Sciences 140 ( 2014 ) 576 - 580.

27.Parsons,Melissa, Glavac,Sonya, Hastings ,Peter, Marshall ,Graham b,c, McGregor ,James a,c, McNeill,Judith b,c, Morley,Phil b,c, Reeve, Ian, Stayner,Richard(2016), Top-down assessment of disaster resilience: A conceptual framework using coping and adaptive capacities, International JournalofDisasterRiskReduction19,1-11.

28.Leykin, D., Lahad, M., Cohen, O., Goldberg, A., Aharonson-Daniel, L., 2013. Conjoint community resiliency assessment measure-28/10 items (CCRAM28 and CCRAM10): a self-report tool for assessing community resilience. Am. J. Community Psychol. 52(3-4), 313-323

29.Cutter, S.L., Barnes, L., Berry, M., Burton, C., Evans, E., Tate, E., Webb, J., 2008. A place-based model for understanding community resilience to natural disasters. Glob. Environ.Chang. 18 (4), 598-606.

30.Cohen, O., Leykin, D., Lahad, M., Goldberg, A., Aharonson-Daniel, L., 2013. The conjoint community resiliency assessment measure as a baseline for profiling and predicting community resilience for emergencies. Technol. Forecast. Soc. Chang. 80 (9), 1732-1741.

31.Ungar, M., 2011. Community resilience for youth and families: facilitative physical and social capital in contexts of adversity. Child Youth Serv. Rev. 33 (9), 1742-1748.

32.Fran H ,Norris, Susan P,Stevens, Betty ,Pfefferbaum, Karen F,Wyche, Rose L,Pfefferbaum(2008), Community Resilience as a Metaphor, Theory, Set of Capacities, and Strategy for Disaster Readiness, Am J Community Psychol, 41:127-150, DOI 10.1007/s10464-007-9156-6.

33.Aldunce P, Beilin R, Handmer J, Howden M(2014), Framing disaster resilience: The implications of the diverse conceptualisations of “bouncing back." Disaster Prev Manag ;23:252-70.

34.Adger WN.(2006) Vulnerability. Glob Environ Chang; 16:268-81.

35.Norris FH, Stevens SP, Pfefferbaum B, Wyche KF, Pfefferbaum RL.(2008) Community resilience as a metaphor, theory, set of capacities, and strategy for disaster readiness. Am J Community Psychol;41:127-50. 36.Fazelnia, Gharib, Hakim dust, Syed Yaser, Yar Mohammadi, Mina, (2015), natural hazard risks in rural areas using GIS with emphasis on landslide factor (Case Study: Rural two thousand city Branch ), research and rural planning, year 4, Issue 2, summer, serial number 10, Ss20- 11. 
37.Meshkini, Aabolfazl, Gahed rahmati, Safar, Shabanzadeh namini, Reza, (2014), analysis of seismic vulnerability of the urban fabric (Case Study: Tehran Municipality area two), Human Geography Research, Volume 46, Number 4, Winter, pp. 856- 843.

38.Farahani, Hossein, Einali, Jamshid, Ghasemi Vieri, Hamid, (2014), the role of capacity development in the management of earthquake risk reduction in rural areas (Case Study: Abhar city, county Sonbolabad, Qazvin), Journal of Housing and Rural Environment, No. 145, spring, pp. 74-63.

39.Delawar, Ali (2013), Methodology of Research in Psychology and Educational Sciences, Publishing virayesh.

40.Asgharizadeh, Ezatollah, Ehsani, Rahim, Vali Pour, Farajollah, (2011), 360 degree performance evaluation methods and techniques managers to decide VIKOR (Case Study Agricultural Engineering Research Institute), Journal - Industrial Management Studies, year IX, Issue 23, winter, pp. 48-21. 